\title{
Allergen avoidance in the secondary and tertiary prevention of allergic diseases: does it work?
}

\author{
Susana Marinho*, Angela Simpson, Adnan Custovic
}

\author{
North West Lung Centre, Wythenshawe Hospital, Manchester M23 9LT, UK
}

Received 2 February 2006; accepted 18 February 2006

KEYWORDS
Allergy;
Allergic disease;
Asthma;
Rhinitis;
Eczema;
Secondary prevention;
Tertiary prevention;
Allergen avoidance II
Mite;
Pets;
Foods

Summary Although allergen avoidance is widely recommended as part of a secondary and tertiary prevention strategy for allergic diseases, a clear-cut demonstration of its effectiveness is still lacking. Ongoing observational secondary prevention cohorts show that sensitisation to mite can lie $n \in v \in$ te $t$ in the short term by allergen avoidance measures, but furthe- foilow ap of these children is needed to show if this effect 'can 'or stisained, as well as to ascertain its impact on allergic disease. $10 \mathrm{c}$ (1-desighed trials are still required before we can give any conclesive adice to our patients. Consiverir she management of allergy, current Evicente suggests that interven tion in chitdren (either single or multifaceted) may be associated $v \mathrm{tn}$ scme bereficial effect on asthma control, but no conclusive eviciencesits regarding rhinitis or eczema. Conversely, there is little evidence to support the recommendation of allergen avoidance methods in adults with asthma and rhinitis. There is a need for an adequately designed trial assessing the effects of a multifaceted intervention in this age group.

(c) 2006 General Practice Airways Group. Published by Elsevier Ltd. All rights reserved.

\section{Contents}

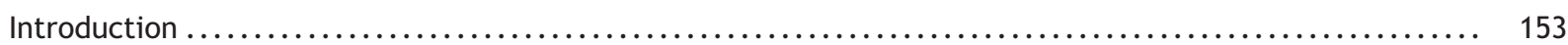

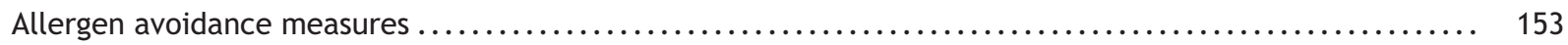

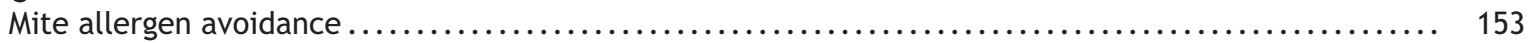

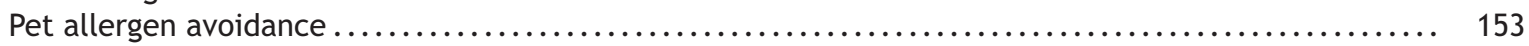

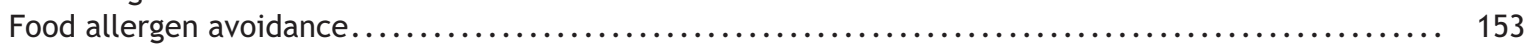

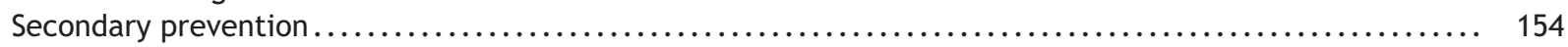

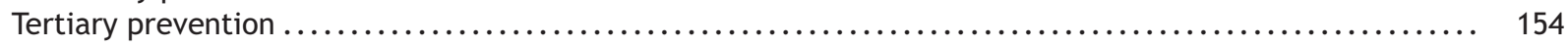

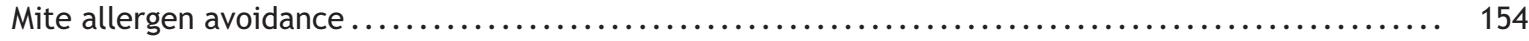

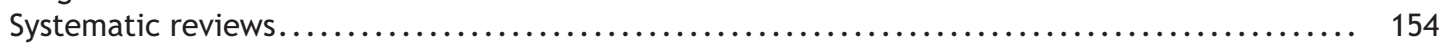

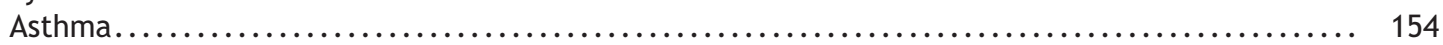

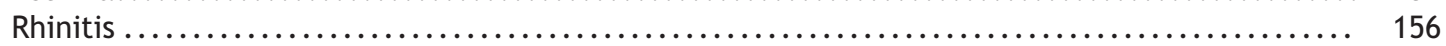

\footnotetext{
* Corresponding author. Tel.: +44 (0) 161291 5031; fax: +44 (0) 1612915020.
}

E-mail address: susana.marinho@manchester.ac.uk (S. Marinho). 


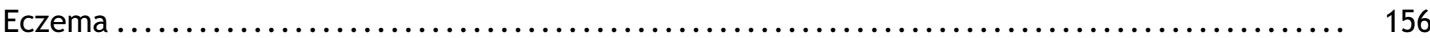

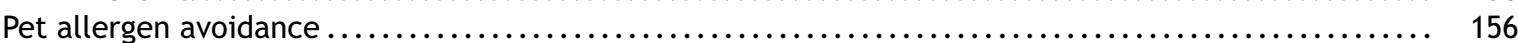

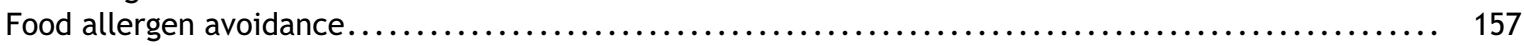

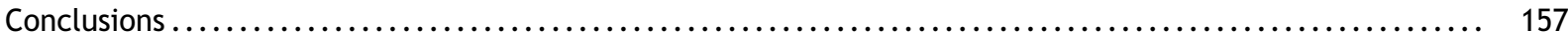

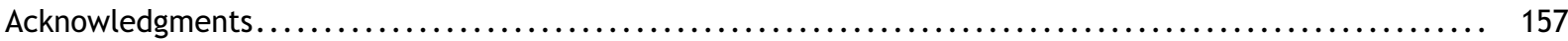

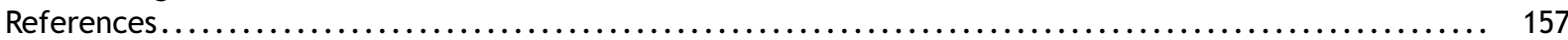

\section{Introduction}

Allergic diseases have a substantial socioeconomic impact [1]. Asthma may be severe and sometimes fatal; rhinitis and eczema, although not usually severe, significantly impair the quality of life of patients [2-4]. Furthermore, asthma and rhinitis are common co-morbidities [2,5], and eczema is frequently associated with these respiratory allergic conditions. In light of this, several secondary and tertiary preventive measures have been tested in studies of different design, often with conflicting results. Amongst the many strategies, allergen avoidance is one of the most frequently investigated. The rationale for the use of environmental control in this context is based on the following:

- sensitisation to inhalant allergens is a major risk factor for asthma, rhinitis and eczema [6]

- exposure to sensitising allergens in allercic individuals causes disease exacerbation $[7 \in$ Q $]$

- complete cessation or exposire leads to ar improvement: ir svinptoms (for axuin)e, in patients with hay feven, the ausence of exposure to grass is associated with a dramatic improvement in symptoms[10]; patients sensitised to cats or dogs only report symptoms when in contact with the pet).

However, observations in occupational asthma suggest that only early cessation of exposure to the offending allergen may lead to a resolution of symptoms; if the exposure continues for a longer period, removal from exposure may not result in symptomatic improvement [3].

\section{Allergen avoidance measures}

\section{Mite allergen avoidance}

Reduction of mites and mite allergens in the home can be attempted in a number of ways, according to the site of contamination. The most effective measure to reduce allergens in bed is to cover the mattress, duvet and pillows with encasings that are impermeable to mite allergens. Nevertheless, since mites can accumulate in exposed bedding as well as in soft toys - these should be washed in a hot cycle (above $55^{\circ} \mathrm{C}$ ) in order to kill the mites. Carpets should be removed and replaced by hard flooring. Other measures that may reduce personal exposure to mites include regular vacuuming of floors and carpets/rugs, replacement of fabric covered upholstered furniture with leather or vinyl coverings, and replacement of curtains with blinds. Chemical methods, such as acaricides, are effective in reducing mite allergen levels in the laboratory setting but difficult to use in the home as their effectiveness depends on repeated application. Since mites require high levels of humidity to survive, another approach to reduce mite population and growth is to control humidity in the home. However, detailed models of the humidity profile of domestic microclimates (e.g. bed, upholstered furniture) are not available, and reducing central humedit, nlay- oe ineffective in reducing luriolty in mite microhabitats like rattress or carpets. Furthermore, this approach critically depencls (0. Othe type of climate and housin \& de:igh - for example, central mechanical ventilation heat recovery units can reduce indoor humidity in Scandinavian houses where outdoor humidity is low and home insulation is good, but are considerably less effective in the UK where outdoor humidity is high and homes are relatively poorly insulated.

\section{Pet allergen avoidance}

The only way to reduce effectively exposure to cat or dog allergen is not to have one in the home. It is worth emphasising that even after permanent removal of an animal from a home it can take many months for the allergen reservoir levels to fall.

Short-term and modest reductions in the airborne allergen achieved by high-efficiency particulate air (HEPA) filter cleaners or regular pet washing are too small to reduce significantly personal inhaled allergen exposure when the pet is kept in the home.

\section{Food allergen avoidance}

Exclusion diets are usually very difficult and complicated to undertake, although this complexity depends on the food and on the age of the patient 
in question. It is generally simpler to exclude some food from the diet of very small breastfed children, but it is extraordinarily complex to attempt the same in an older child or adult. Furthermore, many of the most commonly implicated food allergens are present in a variety of different foods, and frequently only in vestigial "hidden" amounts, which makes the identification of these foods an almost impossible task for patients. Fortunately, the recent awareness of this problem with improvement in labelling of all foods, along with comprehensive dietary advice by an experienced dietician, has begun to simplify this problem.

\section{Secondary prevention}

Secondary preventive measures are designed to halt the progression of disease in individuals who are at high risk for the development of clinical allergy, but who have not yet developed specific symptoms-for example, the prevention of asthma in individuals with eczema, rhinitis, or evidence of allergen sensitisation. The evidence for effective secondary prevention measures is scarce and only a small number of secondary prevention trials using allergen avoidance measures have been conducted. Most research to date has focused on primary and tertiary prevention.

A multicentre study (Stridv of Fuvericion of Allergy in Children of tilurpe SPACE) investigatec the protecti/? e fect of mita avoiconse in highrisk allergic children (with a family history of atopy, asthma, rhinitis, eczema, but not sensitised to mite) [11,12]. In one study [11], 636 young children aged 1.5-5 years were randomised to mite-impermeable mattress covers and specific mite avoidance advice vs. general advice only. The rate of sensitisation to mite after one year was reduced in the active group. A similar study and intervention including 242 children aged 5-7 years was reported by another group [12]. After one year, fewer children were newly sensitised to mite in the active group, with a trend for fewer wheezing symptoms. These studies show that sensitisation to mite can be prevented in the short term. However, further follow-up of these children is essential to show if this effect can be sustained, as well as to ascertain its impact on the natural history of allergic disease.

\section{Tertiary prevention}

The objective of tertiary prevention is to prevent exacerbations, thereby improving disease control and reducing medication needs.
Exposure to different allergens can trigger asthma attacks and exacerbate rhinitis and eczema in sensitised individuals $[7,9,13,14]$. Consequently, avoiding allergens which cause symptoms in those who are sensitised seems logical, and should lead to an improvement in disease control. This type of intervention works for patients with occupational asthma, where identification and complete avoidance of the culprit trigger is feasible and associated with a dramatic improvement in symptoms, having even been shown to induce a reduction in sensitisation in latex-allergic health care workers [15]. However, only cessation of exposure early in the natural history of the disease will result in the resolution of symptoms.

Several studies (mostly carried out at high altitude or hospitals) have suggested clinical benefits from allergen avoidance $[16,17]$. However, attempts to replicate these findings in the patients' homes have provided conflicting results.

\section{Mite allergen avoidance}

A set of measures mentioned in the previous section can be used to reduce mite aller $\in \mathrm{n}$; (i) the home [18]. However, these ineerven ions are costly, and the critical question is whether their use has any inlpace on disease in real life.

\section{systenatic reviews}

A recent update of the Cochrane meta-analysis comprising 49 studies including 2733 patients (literature search until June 2004), reported no effect of the interventions and concluded that current methods of mite allergen avoidance should not be recommended for mite-sensitive asthmatics [19]. Similarly, a Cochrane systematic review of mite avoidance measures for perennial allergic rhinitis published in 2001 reported no beneficial effect of physical or chemical intervention, concluding that there is little evidence that a reduction in mite exposure will lead to a sustained improvement in patient's outcomes (however, only four small trials satisfied the inclusion criteria, all of which were judged to be of poor quality) $[20,21]$. There are no systematic reviews assessing the effect of mite avoidance in eczema.

\section{Asthma}

Studies in adults. Three studies investigating mite avoidance in the treatment of asthma in adults (each of very different design and including in total results on only 98 mite-allergic patients) have been much cited as showing a beneficial effect. In 1986, Walshaw and Evans [22] reported the results of a multifaceted intervention which successfully 
reduced mite exposure (involving plastic mattress encasings, linoleum bedroom floor coverings, or regular vacuuming and a washing and cleaning regime over a one-year period). The active group showed a small improvement in peak expiratory flow rate (PEFR) and bronchial hyperreactivity (BHR). Van der Heide et al. published in 1997 the findings of a three-way study of air cleaners and encasings in allergic adults with asthma, where they found a small improvement in BHR in the group randomised to receive both the active air cleaners and covers at 6 months [23]. In 2001, Htut et al. [24] published a study investigating the use of active heat-steam treatment in homes with or without the use of a special home ventilation system, reporting a sustained reduction in allergen levels in all the study participants and a significant improvement in BHR.

Considering more recent studies, the largest randomised double-blind, placebo-controlled (RDBPC) trial assessing the effect of miteimpermeable bed covers as a single intervention has been performed in the UK, involving over 1000 adults with physician-diagnosed asthma and on inhaled corticosteroids (ICS) [25]. The patients were selected irrespective of allergen sensitisation (two-thirds had positive mite-specific IgE) and allergen exposure status (approximately one in four beds had mite allergen levels grea er han $10 \mu \mathrm{g} / \mathrm{g})$. The study comprited tivo periods, each lasting six mont'is: the first, with patients on stalote ICS treatment, and the secolid wit o d concrolled ICS step-down regime (steroid reduction continued until either all ICS had been discontinued or asthma control had deteriorated according to predefined criteria). The primary outcomes were morning PEFR over a four-week period during month 6 in comparison to run-in, and the proportion discontinuing ICS during months 7-12. There was no difference in either of the primary outcomes for the whole group or the mite-sensitive subgroup, or in any of the secondary outcomes. Further analysis of the subgroup of 130 patients with high mite-specific $\lg \left(\geq 10 \mathrm{kU}_{\mathrm{A}} / \mathrm{l}\right)$ and high baseline mite allergen exposure $(>10 \mu \mathrm{g} / \mathrm{g}$ of mattress dust) did not demonstrate any differences in any of the outcomes between the active and placebo groups. One other RDBPC study carried out in the UK but selecting adult patients with asthma on ICS $(n=55)$ only if sensitised to mite (mite-specific $\lg \mathrm{E}>0.7 \mathrm{kU}_{\mathrm{A}} / \mathrm{l}$ ) and exposed to high levels of this allergen in their mattresses (Der $p$ $1>2 \mu \mathrm{g} / \mathrm{g}$ ), did not identify any effect of miteproof encasings in any of the measured outcomes (PEFR, asthma symptoms and medication) [26].
These two trials showed convincingly that a single intervention with mite-proof encasings involving the mattress, duvet and pillows is ineffective in the long-term treatment of asthma in adults, even in highly mite-allergic individuals exposed to high levels of mite allergen in whom this type of intervention is most likely to have an effect.

Another RDBPC trial published in 2005, investigating the effect of mite-proof encasings on the quality of life (QoL) of mite-sensitised patients $(n=224)$ with asthma and/or rhinitis and/or eczema, failed to prove a significant effect of this intervention between the active and control groups regarding the quality of life scores, although these were significantly lower in both groups in comparison to the general population [27]. Several other recent studies investigating the same intervention failed to prove a beneficial effect $[19,28,29]$.

A recent RDBPC trial also investigating the effectiveness of mite-impermeable bed covers performed in the Netherlands included 52 mitesensitised asthmatic patients (aged 12-60 years) and had a 9-week intervention period. The authors demonstrated an improverigent in PEF $R$ in the active compared with the laceso group, but not in any of :he cther outcome melasures [30]. Unfortunately, long-term follov-tif this population has not heeriplelformeá.

Studies in children. A recent large study in 937 children (aged 5-11 years) from seven US inner-city areas with high levels of poverty, investigated the effectiveness of a comprehensive environmental control regime [31]. Participants had physiciandiagnosed poorly controlled moderate to severe asthma (despite this, less than half of the subjects were receiving appropriate controller treatments) and at least one positive skin test. The intervention (lasting one year) was tailored to the child's sensitization and exposure status, included advice on reduction in passive smoke exposure when appropriate, and focussed on the education of the parent/caregiver. Allergenimpermeable mattress and pillow encasings and high filtration vacuum cleaners were supplied to homes of cases, but no attempt was made to introduce placebo devices into control homes. This wide-range intervention significantly reduced mite and cat allergen levels and was also associated with significantly more symptom-free days over a twoyear period in the active compared to the control group. The increase in symptom-free days was seen predominantly in those children with larger $(>50 \%)$ reductions in allergen (mite and cockroach) 
levels. The number of emergency room visits was also reduced during the intervention year, and many of the secondary outcome measures showed a significant improvement, or a trend towards improvement in the active compared with the control group.

In another recent publication, Halken et al. [32] reported the results of a RDBPC trial on the effect of a single intervention (lasting one year) with mite-proof mattress and pillow encasings in 52 mite-allergic children with physician-diagnosed asthma exposed to mattress Der $p 1$ levels $>2 \mu \mathrm{g} / \mathrm{g}$. There was a significant decrease in the dose of ICS (approximately 50\%), observed only in the active group.

Several other previous studies have indicated that an intervention including mattress encasings, combined or not with other mite avoidance measures (such as the use of acaricides and washing instructions), is associated with an improvement in BHR in mite-sensitised asthmatic children [33] or in forced expiratory volume in one second $\left(\mathrm{FEV}_{1}\right)$ [34], or a reduction in acute visits due to asthma [35].

\section{Rhinitis}

A recent RDBPC trial investigated the effectiveness of mite-impermeable encasings in $\mathbf{2 7 9}$ mite-allergic patients (sensitised and with a positive rasat challenge to mite) with perennial al (e-rgich hinitis, aged 8-50 years [36]. There nas a inarked and significant reduction i, the level of matirel:0er $\mathrm{p} 1$ in the active compared to the diaceivo group. Nevertheless, both groups reported a decrease in symptom scores (primary outcome measure) during the 12-month follow-up period, with no difference between groups; similarly there was no difference between the groups in any of the secondary outcome measures. This is the first RDBPC trial on the effect of mite-proof encasings on the treatment of rhinitis and, similarly to the most recent publication cited previously [27], it failed to demonstrate a beneficial effect. Other studies on mite avoidance measures in rhinitis have either been open or have used HEPA filters [37] or acaricides [38], showing minimal clinical benefit.

\section{Eczema}

Besides the previously quoted study investigating the effect of mite-impermeable encasings on the QoL of patients with asthma and/or rhinitis and/or eczema [27], the most recent study on mite avoidance in the management of patients with eczema was published in 2002 [39]. This RDBPC trial, which included 86 mite-allergic patients with eczema (aged 8-50 years), failed to show any significant differences in clinical parameters between the active (using mite-proof encasings for 1 year) and control groups, despite the reduction in mite exposure. Another study with a similar design in 20 adults (intervention comprising miteimpermeable encasings and acaricides), also failed to show an improvement in overall disease activity [40]. An earlier study in which half the patients were children, using a combination of encasings, acaricides and high filtration vacuum cleaners for six months, demonstrated a significantly greater improvement in the severity score and area affected in the active compared to the control group [41].

To summarize, most of the published studies in adults demonstrate that the use of allergenimpermeable covers as a single intervention is clinically ineffective in asthma management. While it remains possible that a multifaceted intervention combining this strategy with other mite control measures in carefully selected patients could have some effect, this has not as yet been addressed in an adequately designed study. In contrast, several small trials of allergen-impermeable bed encasings as a single intervention in asthmatic chldren have reported benefits, as Gid more colnprehensive interventions in chitcren living in poor quality hou ins, the applicability of these findings to more affluent Ghlidiereremains to be investigated. Regaldiry minitis and eczema, the most recent well-designed studies on mite avoidance measures have failed to demonstrate a clinical benefit.

\section{Pet allergen avoidance}

Although it is accepted that there is a significant clinical improvement associated with the absence of contact with the sensitizing pet in cat- or dog-allergic patients-based on clinical experience and observational studies [42] - it is also known that these allergens are very difficult to eradicate from the home, and even then exposure may be maintained as cat and dog allergens are ubiquitous [43].

Three studies have addressed the effects of pet allergen control measures in pet-sensitised pet owners. Two showed small improvements in asthma-related outcomes [44,45], but one did not [46]. However, the number of subjects was small and larger studies would be needed before public health recommendations can be made. A Cochrane review reported no beneficial effect of pet allergen control measures for allergic asthma in children and adults-however, only two small studies met the inclusion criteria [47]. 


\section{Food allergen avoidance}

It is difficult to get patients to comply with food allergen avoidance. The beneficial effects of food avoidance in food-allergic patients without other allergic disorders are unambiguous, this approach being indeed the mainstay of their treatment. Some controversy still exists, however, regarding the role of exclusion diets in patients with combined eczema and food sensitivity. The few small studies on this issue, most investigating the impact of an elemental diet, showed no or limited benefit [48-50].

\section{Conclusions}

Although allergen avoidance is widely recommended as part of a secondary and tertiary prevention strategy for allergic diseases, a clearcut demonstration of its effectiveness is lacking. Considering the management of allergy, there is little evidence to support the use of simple indoor allergen avoidance methods in adults with allergic disease. As for the effects of a multifaceted intervention there are, as yet, no adequately powered studies upon which to make an informed decision in this age group. In contrast, the majpritv of studies in children suggest that environental control measures may be of sone benefit. The reasons for thil are nci clear. but the siclalion may be ariatogous to that of c\& pational asthma, when prompt removal from a sensitizing allergen is associated with a better long-term outcome than after prolonged exposure.

\section{Acknowledgments}

Susana Marinho is sponsored by a grant from Fundação para a Ciência e Tecnologia, Portugal POCI 2010.

\section{References}

[1] Gupta R, Sheikh A, Strachan DP, Anderson HR. Burden of allergic disease in the UK: secondary analyses of national databases. Clin Exp Allergy 2004;34:520-6.

[2] Bousquet J, van Cauwenberge P, Khaltaev N. Allergic rhinitis and its impact on asthma. J Allergy Clin Immunol 2001;108:S147-334.

[3] GINA workshop report. Global strategy for asthma management and prevention. National Heart Lung and Blood Institute/World Health Organisation 2005.

[4] Leung DY, Bieber T. Atopic dermatitis. Lancet 2003; 361:151-60.
[5] Simons FE. Allergic rhinobronchitis: the asthma-allergic rhinitis link. J Allergy Clin Immunol 1999;104:534-40.

[6] Simpson BM, Custovic A, Simpson A, et al. NAC Manchester Asthma and Allergy Study (NACMAAS): risk factors for asthma and allergic disorders in adults. Clin Exp Allergy 2001;31:391-9.

[7] Custovic A, Taggart SC, Francis HC, Chapman MD, Woodcock A. Exposure to house dust mite allergens and the clinical activity of asthma. J Allergy Clin Immunol 1996;98:64-72.

[8] Rosenstreich DL, Eggleston P, Kattan M, et al. The role of cockroach allergy and exposure to cockroach allergen in causing morbidity among inner-city children with asthma. N Engl J Med 1997;336:1356-63.

[9] Langley SJ, Goldthorpe S, Craven M, Morris J, Woodcock A, Custovic A. Exposure and sensitization to indoor allergens: association with lung function, bronchial reactivity, and exhaled nitric oxide measures in asthma. J Allergy Clin Immunol 2003;112:362-8.

[10] O'Meara TJ, Sercombe JK, Morgan G, Reddel HK, Xuan W, Tovey ER. The reduction of rhinitis symptoms by nasal filters during natural exposure to ragweed and grass pollen. Allergy 2005;60:529-32.

[11] Tsitoura S, Nestoridou K, Botis P, et al. Randomized trial to prevent sensitization to mite allergens in toddlers and preschoolers by allergen reduction and education: one-year results. Arch Pediatr Adolesc Med 2002;156:1021-7.

[12] Arshad SH, Bojarskas J, Tsitoura S, et al. Prevention of sensitization to house dust mite by allergen avoidance in school age children: a randomized controlled study. Clin Exp Allergy 2002;32:843-9.

[13] Horak F, Toth J, Hirscheneh, ec al. Effect of continuous alle $g=n$ challenge on clinical symptoms and tredicor elease in dust-mite-allergic patients. Allergy i998;53:68-72."

[14] Kramer $L$, $\mathcal{W}^{\prime} \in$ id ingers, Darsow U, Mohrenschlager M, Ring , 3 eh rendt $H$. Seasonality in symptom severity influenced b) temperature or grass pollen: results of a panel study in children with eczema. J Invest Dermatol 2005;124: 514-23.

[15] Nettis E, Colanardi MC, Ferrannini A. Type I latex allergy in health care workers with latex-induced contact urticaria syndrome: a follow-up study. Allergy 2004;59:718-23.

[16] Valletta EA, Comis A, Del Col G, Spezia E, Boner AL. Peak expiratory flow variation and bronchial hyperresponsiveness in asthmatic children during periods of antigen avoidance and reexposure. Allergy 1995;50: 366-9.

[17] Platts-Mills TA, Tovey ER, Mitchell EB, Moszoro H, Nock P, Wilkins SR. Reduction of bronchial hyperreactivity during prolonged allergen avoidance. Lancet 1982;2:675-8.

[18] Simpson A, Simpson B, Custovic A, Craven M, Woodcock A. Stringent environmental control in pregnancy and early life: the long-term effects on mite, cat and dog allergen. Clin Exp Allergy 2003;33:1183-9.

[19] Gotzsche PC, Johansen HK, Schmidt LM, Burr ML. House dust mite control measures for asthma. Cochrane Database Syst Rev 2004:CD001187.

[20] Sheikh A, Hurwitz B. House dust mite avoidance measures for perennial allergic rhinitis. Cochrane Database Syst Rev 2001:CD001563.

[21] Sheikh A, Hurwitz B. House dust mite avoidance measures for perennial allergic rhinitis: a systematic review of efficacy. Br J Gen Pract 2003;53:318-22.

[22] Walshaw MJ, Evans CC. Allergen avoidance in house dust mite sensitive adult asthma. Q J Med 1986;58:199-215.

[23] van der Heide S, Kauffman HF, Dubois AE, de Monchy JG. Allergen reduction measures in houses of allergic asthmatic 
patients: effects of air-cleaners and allergen-impermeable mattress covers. Eur Respir J 1997;10:1217-23.

[24] Htut T, Higenbottam TW, Gill GW, Darwin R, Anderson PB, Syed N. Eradication of house dust mite from homes of atopic asthmatic subjects: a double-blind trial. J Allergy Clin Immunol 2001;107:55-60.

[25] Woodcock A, Forster L, Matthews E, et al. Control of exposure to mite allergen and allergen-impermeable bed covers for adults with asthma. $N$ Engl J Med 2003;349:225-36.

[26] Luczynska C, Tredwell E, Smeeton N, Burney P. A randomized controlled trial of mite allergen-impermeable bed covers in adult mite-sensitized asthmatics. Clin Exp Allergy 2003;33:1648-53.

[27] Terreehorst I, Duivenvoorden HJ, Tempels-Pavlica Z, et al. The effect of encasings on quality of life in adult house dust mite allergic patients with rhinitis, asthma and/or atopic dermatitis. Allergy 2005;60:888-93.

[28] Gotzsche PC, Hammarquist C, Burr M. House dust mite control measures in the management of asthma: metaanalysis. BMJ 1998;317:1105-10.

[29] Gotzsche PC, Johansen HK, Burr ML, Hammarquist C. House dust mite control measures for asthma. Cochrane Database Syst Rev 2001:CD001187.

[30] van den Bemt L, van Knapen L, de Vries MP, Jansen $M$, Cloosterman S, van Schayck CP. Clinical effectiveness of a mite allergen-impermeable bed-covering system in asthmatic mite-sensitive patients. J Allergy Clin Immunol 2004;114:858-62.

[31] Morgan WJ, Crain EF, Gruchalla RS, et al., the InnerCity Asthma Study Group. Results of a Home-Based Environmental Intervention among Urban Children with Asthma. N Engl J Med 2004;351:1068-80.

[32] Halken S, Host A, Niklassen U, et al. Effect of mattres and pillow encasings on children with astrma and nc use dust mite allergy. J Allergy ri:n linm unc I ग003,111:169-76.

[33] Shapiro CE, W'ighol T;, Chinn T, et al. Hous dus: mite

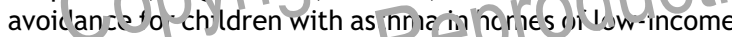
families. J Allergy Clin Immunot is?\%; 103:1069-74.

[34] Carswell F, Birmingham K, Oliver J, Crewes A, Weeks J. The respiratory effects of reduction of mite allergen in the bedrooms of asthmatic children-a double-blind controlled trial. Clin Exp Allergy 1996;26:386-96.

[35] Carter MC, Perzanowski MS, Raymond A, Platts-Mills TAE. Home intervention in the treatment of asthma among innercity children. J Allergy Clin Immunol 2001;108:732-7.

[36] Terreehorst I, Hak E, Oosting AJ, et al. Evaluation of impermeable covers for bedding in patients with allergic rhinitis. N Engl J Med 2003;349:237-46.

[37] Reisman RE, Mauriello PM, Davis GB, Georgitis JW, DeMasi $J M$. A double-blind study of the effectiveness of a high- efficiency particulate air (HEPA) filter in the treatment of patients with perennial allergic rhinitis and asthma. J Allergy Clin Immunol 1990;85:1050-7.

[38] Geller-Bernstein C, Pibourdin JM, Dornelas A, Fondarai J. Efficacy of the acaricide: acardust for the prevention of asthma and rhinitis due to dust mite allergy, in children. Allerg Immunol (Paris) 1995;27:147-54.

[39] Oosting AJ, Bruin-Weller MS, Terreehorst I, Tempels-Pavlica Z. Aalberse RC, de Monchy JGR, van Wijk RG, BruijnzeelKoomen CAFM. Effect of mattress encasings on atopic dermatitis outcome measures in a double-blind, placebocontrolled study: The Dutch mite avoidance study. J Allergy Clin Immunol 2002;110:500-6.

[40] Gutgesell C, Heise S, Seubert S, et al. Double-blind placebo-controlled house dust mite control measures in adult patients with atopic dermatitis. $\mathrm{Br} \mathrm{J}$ Dermatol 2001;145:70-4.

[41] Tan BB, Weald D, Strickland I, Friedmann PS. Doubleblind controlled trial of effect of housedust-mite allergen avoidance on atopic dermatitis. Lancet 1996;347:15-8.

[42] Shirai T, Matsui T, Suzuki K, Chida K. Effect of Pet Removal on Pet Allergic Asthma. Chest 2005;127:1565-71.

[43] Almqvist C, Larsson PH, Egmar AC, Hedren M, Malmberg $P$, Wickman $M$. School as a risk environment for children allergic to cats and a site for transfer of cat allergen to homes. J Allergy Clin Immunol 1999;103: 1012-7.

[44] Francis H, Fletcher G, Anthony C, et al. Clinical effects of air filters in homes of asthmatic adults sensitized and exposed to pet allergen. Clin Lxp - llergy 2003;33: $101-5$.

[45] van der H'ele s, var. - alaeren WM, Kauffman HF, Dubois AE, oe Alonchy JG. Clinical effects of air cleaners in homes of asthmatic chlildie 1 iensitized to pet allergens. J Allergy Clin-In n un ol $190 \% 104: 447-51$.

[46] Noud RA, Johnson EF. Van Natta ML, Chen PH, Eggleston PA. A placebo-controlled trial of a HEPA air cleaner in the treatment of cat allergy. Am J Respir Crit Care Med 1998;158:115-20.

[47] Kilburn S, Lasserson TJ, McKean M. Pet allergen control measures for allergic asthma in children and adults. Cochrane Database Syst Rev 2003:CD002989.

[48] Lever R, MacDonald C, Waugh P, Aitchison T. Randomised controlled trial of advice on an egg exclusion diet in young children with atopic eczema and sensitivity to eggs. Pediatr Allergy Immunol 1998;9:13-9.

[49] Mabin DC, Sykes AE, David TJ. Controlled trial of a few foods diet in severe atopic dermatitis. Arch Dis Child 1995;73:202-7.

[50] Devlin J, David TJ, Stanton RH. Elemental diet for refractory atopic eczema. Arch Dis Child 1991;66:93-9.

Available online at www.sciencedirect.com

science@Direct.

Available online at http://www.thepcrj.com 